\title{
Performance Measurements of Energy Storage Systems and Control Strategies in Real-world e-bikes
}

\author{
Sergio Saponara*, Riccardo Moras*, Roberto Roncella*, Roberto Saletti*, David Benedetti ${ }^{\S}$ \\ *Dipartimento di Ingegneria dell'Informazione, Università di Pisa, I-56122 Pisa, Italy \\ ${ }^{\S}$ Carbon Dream, I-50028 Tavarnelle Val di Pesa (FI), Italy
}

\begin{abstract}
The paper presents a measurement campaign (electrical, thermal and user comfort) for the performance characterization of energy storage systems in real-world electric bicycles. Specific sensors were added to characterize three vehicles which differ for electric motor, energy storage system size and control strategies. The controller can implement energy recovery strategies when braking and change the level of electric assistance depending on the desired trade-off between the comfort of the driver and the battery duration. Experimental results show that a control strategy aiming at preserving the SOC (State-Of-Charge), together with regenerative braking, can ensure very long battery duration with no need of recharge. The SOC is kept at about $50 \%$ for a long period. Instead, control strategies optimizing the full comfort of the driver by maximizing the level of assistance can ensure real-world e-bicycle missions of about $2 \mathrm{~h}$ and $40 \mathrm{~km}$, when the SOC of the battery drops down from $95 \%$ to $5 \%$.

Index Terms- e-bicycle, e-bike, measurements for electric vehicles, on-board sensors
\end{abstract}

\section{INTRODUCTION}

The interest in electric vehicles is continuously increasing to address environmental issues. Electrically assisted bicycles (e-bicycles) can ensure the mobility requirements in terms of speed and covered distance in urban scenarios, addressing problems such as emissions, parking, restricted circulation areas, which are the main issues in crowded cities. The market of e-bicycles is on the order of several tens of millions sold every year worldwide [1]. An e-bicycle is typically equipped with a brushless electric motor that gives assistance to the user up to maximum speed and power values, $25 \mathrm{~km} / \mathrm{h}$ and $250 \mathrm{~W}$ respectively, according to Italian laws [2]. The covered distance and the type of assistance will depend on: the energy storage subsystem, based on emerging Li-ion battery modules with or without a BMS (Battery Management System) or still on mature and less efficient lead- or nickel- based batteries [3]; the motor controller that may also implement advanced services like regenerative braking; the set of sensors and of bicycle-user communication interfaces installed on the vehicle; the lighting subsystem which can be based on LEDs powered by a dynamo (mechanical conversion) or the battery unit. The technological trade-off also includes aspects like the cost and weight of the vehicle. Several state of the art solutions have been proposed from very simple vehicles, still with lead or nickel batteries and without BMS, regenerative braking, user-vehicle interfaces and sensors, to complex electrification systems for high-end bicycles. As bicycles becomes more advanced, they are provided with a richer set of sensors (torque, speed, voltage, current and temperature of the motor and the battery), [4] and [5], utilized for the bicycle control but also for remote vehicle data logging or presentation on the user dashboard. Notwithstanding the high environmental and economical interest on e-bicycles, an exhaustive and comparative measuring campaign and analysis of the different solutions is missing in the literature. This is particularly true with reference to the energy storage subsystem and its controlling strategy which is strictly related to the assistance strategy. To this aim, this paper presents a measurement campaign for the performance characterization of energy storage systems in real-world e-bicycles. Different vehicles are considered for the tests, described in Section II, which differ for the characteristics of the electric motor and energy storage system, the controlling strategies, the sets of sensors and the user interface. Performance characterization is addressed in Sections III and IV in various operating modes, from full assistance strategies to SOC-oriented strategy, with and without regenerative braking. Experimental results and lesson learnt are reported. Conclusions are drawn in Section V.

\section{VEHICLES UNDER TEST AND TEST STRATEGY}

\section{A. Vehicles under test}

Three different e-bicycles were tested. A stock e-bicycle (Atala E-Scape [6]), a mountain-bike (MTB) equipped with an electrification kit (Nine Continent [7]) and a city-bike with a smart electrified wheel (Zehus Bike+ [8]). The bicycles are shown in the photographs of Fig. 1(a), 1(b) and 1(c), respectively. The Atala Escape is a standard e-bicycle with a rear wheel hub $250 \mathrm{~W}$ brushless motor, with geared transmission, and an external and removable $36 \mathrm{~V}, 10 \mathrm{~A} \mathrm{~h} \mathrm{Li-ion} \mathrm{battery} \mathrm{pack.}$ The battery pack is organized as a string of 10 series-connected cells (10S1P configuration). The battery is not provided with an integrated BMS, so that the protection against undervoltage is implemented in the motor controller. As the battery is not equipped with any sensors, we added a temperature sensor inside the battery pack (Texas Instruments LM19) and a current sensor (Allegro Microsystem ACS711), so that the battery voltage, current and temperature can be measured. The Nine Continent electrification kit consists of a rear wheel hub $800 \mathrm{~W}$ brushless motor, with direct drive, and a motor controller. The controller limits the motor power to $250 \mathrm{~W}$, as required by 


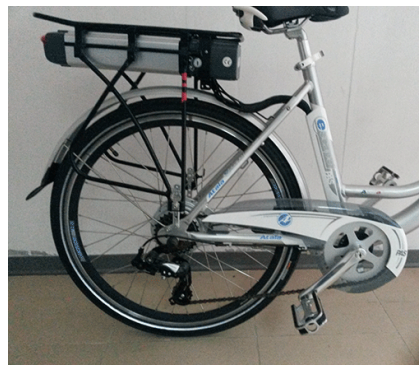

(a) Atala Escape with $250 \mathrm{~W}$ Brushless Motor and $10 \mathrm{Ah}, 36 \mathrm{~V} \mathrm{Li}-\mathrm{Ion}$ Battery Pack

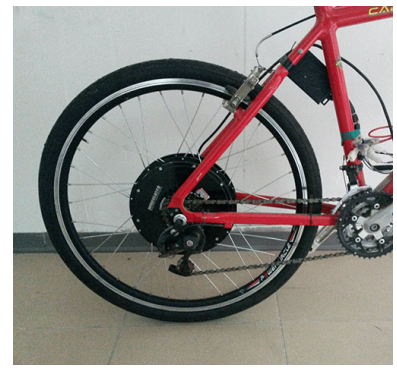

(b) Kit Nine Continent with $800 \mathrm{~W}$ (c) Zehus Bike+ with all in one $250 \mathrm{~W}$ Brushless Motor and 10 Ah, $36 \mathrm{~V}$ Brushless Motor and 5.4 Ah, 29.6 V Li-Ion Battery Pack

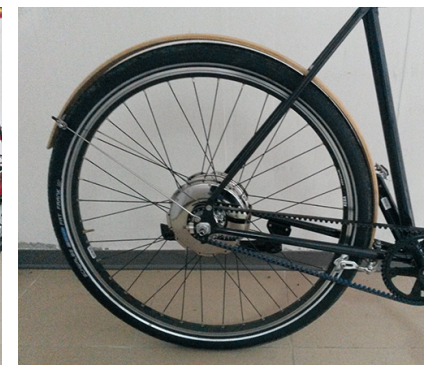

Li-Ion Battery Pack

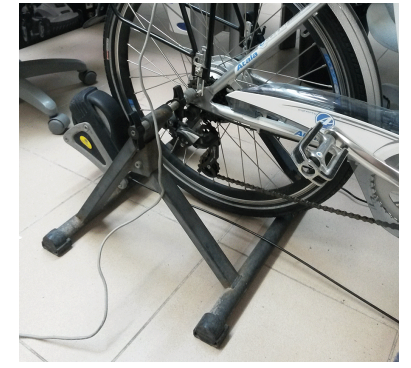

(d) Indoor bicycle trainer

Figure 1: Tested e-bicycles

the Italian laws [2], and implements the battery undervoltage protection. The kit does not contain a battery pack, so the same battery from the Atala Escape was used, sensored in our lab as mentioned above, so that battery voltage, current and temperature values are available also in this case. The Zehus Bike+ is an all-in-one system, as all the components (motor, transmission, battery pack, BMS and the controller board) are contained into the rear wheel hub. The motor is a $250 \mathrm{~W}$ brushless motor with geared transmission and the battery is a $29.6 \mathrm{~V}, 5.4 \mathrm{~A} \mathrm{~h}, \mathrm{Li}$-ion pack. The pack is organized as a string of 8 series-connected cells (8S1P configuration). Battery current and voltage, slope and motor speed sensors are embedded in the hub, but they are not available outside. A Controller Area Network (CAN) bus and a Bluetooth (BT) communication link with undocumented protocols are also available. However, the system is provided with a BT connected software application with which the main parameters of the system are shown on a remote terminal (smartphone, tablet).

The main characteristics of the e-bicycles under test are summarized in Table I. It is worth noting that the Zehus ebicycle has an energy storage subsystem with a lower capacity that leads to a much lower weight (half and one third with respect to the Atala and Nine Continent weight, respectively). Nevertheless, the Zehus system is characterized by a specific energy storage (Wh/kg) comparable to the others.

The three vehicles chosen for the experimental characterization campaign represents a good figure of the state-of-theart in e-bicycle market. Zehus system is very appealing for lightweight bicycles made of new materials (like Carbon-FiberReinforced-Plastic) or for urban scenarios where the distances to cover are limited to few dozens of $\mathrm{km}$ per day and a low weight is mandatory. Atala is a more versatile e-bicycle based on a standard city-bike frame. This kind of bicycle allows the user to take small journeys, even outside the city, since the range is of about $70 \mathrm{~km}$. The energy content of the battery allows the user to ride with high level of pedaling assistance, with the drawback of an heavier bicycle. The Nine Continent kit is a good example of low budget solution, by which an ordinary bicycles is electrified, regardless of the vehicle type [9]. The major drawbacks are the weight, the consequent low
Table I: Main characteristics of the tested e-bicycles

\begin{tabular}{llll}
\hline & Atala Escape & $\begin{array}{l}\text { Nine } \\
\text { Continent }\end{array}$ & Zehus Bike+ \\
\hline PEDELEC compliance & Yes & Yes & Yes \\
Cell type & Li-Ion & Li-Ion & Li-Ion \\
Capacity & $10 \mathrm{~A} \mathrm{~h}$ & $10 \mathrm{~A} \mathrm{~h}$ & $5.4 \mathrm{~A} \mathrm{~h}$ \\
Battery configuration & $10 \mathrm{~S} 1 \mathrm{P}$ & $10 \mathrm{~S} 1 \mathrm{P}$ & $8 \mathrm{~S} 1 \mathrm{P}$ \\
Nominal voltage & $36 \mathrm{~V}$ & $36 \mathrm{~V}$ & $29.6 \mathrm{~V}$ \\
Nominal energy & $360 \mathrm{Wh}$ & $360 \mathrm{Wh}$ & $154.8 \mathrm{Wh}$ \\
Maximum motor power & $250 \mathrm{~W}$ & $800 \mathrm{~W}$ & $250 \mathrm{~W}$ \\
Motor type & Brushless & Brushless & Brushless \\
Trasmission type & Geared & Direct-drive & Geared \\
System weight $*$ & $7 \mathrm{~kg}$ & $11 \mathrm{~kg}$ & $3.2 \mathrm{~kg}$ \\
Specific energy & $51.4 \mathrm{Wh} / \mathrm{kg}$ & $32.7 \mathrm{Wh} / \mathrm{kg}$ & $48.4 \mathrm{Wh} / \mathrm{kg}$ \\
Charging cycles & 500 & 500 & 1000 \\
\hline
\end{tabular}

* Total weight of the battery, the motor controller,

the motor and the wiring loom

specific energy value, and the overall performance. Atala and Zehus e-bicycles allow the user to choose between different operating modes. Atala implements a "Normal" mode and an "Eco" mode that trade off the motor support and the available charge in the battery. Instead, Zehus system implements three main riding modes: the "eBike" (characterized by maximum motor assistance), the "Range Extended" (assistance is slightly reduced but range is improved) and the "Bike+" (battery charge maintenance priority). This system is the only one among the three that implements regenerative braking, i.e. the energy recovery when braking. This function can be enabled automatically by the controller or by pedaling backwards.

\section{B. On-board Sensors of Zehus Bike+}

Zehus Bike+ is a high-end e-bicycle, a rather complex and expensive vehicle. Therefore, a large number of specific sensors are expected to be used in the system. In particular, it is reported that a 3 axis accelerometer, a 3 axis gyroscope, battery voltage and current, pedaling torque, motor speed and temperature sensors are embedded in the hub. Therefore, the communication system is in its turn more complex. In particular, Bluetooth 2.3 is used for the user interface via a smartphone, and the CAN-bus for servicing and debugging. 


\section{Characterization Strategy}

The experimental characterization campaign was carried out following two different test methodologies. First, each e-bicycle was tested on an indoor bicycle trainer; then the Zehus Bike+ was also subjected to real-world road tests in order to evaluate the overall performance and to rate the user comfort with different functioning modes.

Two different data acquisition procedures were adopted, according to the test scenarios. An example of indoor test with the Atala on the bicycle trainer is shown in Fig. 1(d). A National Instrument USB-6009 DAQ was used to acquire the voltage, current and temperature from the sensorized battery. A sampling frequency of $10 \mathrm{~Hz}$ was considered sufficient. The sensor signals were filtered with a $4 \mathrm{~Hz}$ anti-aliasing low-pass filters before the acquisition. Each test consists of a constant speed run, which starts with a fully charged battery and ends when the undervoltage protection on the controller is activated.

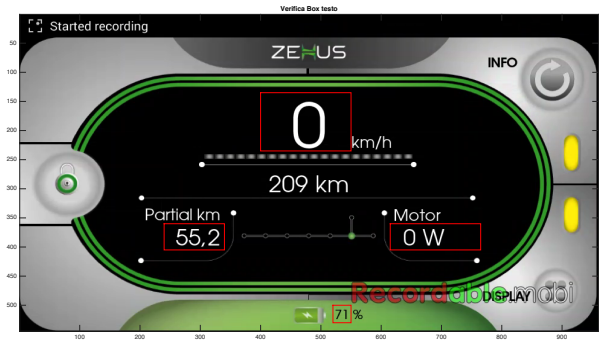

Figure 2: Outdoor tests approach: Bike+ APP video frame

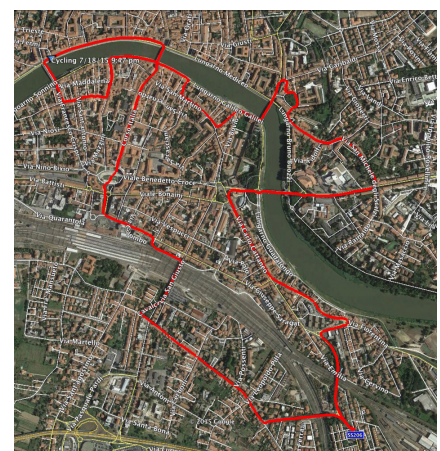

Figure 3: Standard lap for the road tests, $10 \mathrm{~km}$ with 8 uphill

The acquisition procedure for the road tests was different because the only documented data are visible on the user smartphone acting as virtual dashboard, where the software application (APP) is running and showing data (of the battery status, power, speed and distance of the trip) obtained from the e-bicycle controller. As the communications protocols are unknown, the data were acquired by video-recording the smartphone screen when the control and logging APP was running, as shown in Fig. 2. The video recording speed was set to $8 \mathrm{fps}$. The footages were then off-line processed with Matlab and the data values were recognized using an optical character recognition function. The road tests were performed on a lap inside the historical town of Pisa repeated several times, as shown in Fig. 3. As the city of Pisa stands on a rather flat ground, the test route was chosen in order to include the largest possible number of bridges and overpasses while remaining in a urban context with frequent starts and stops. The length of the lap was about $10 \mathrm{~km}$, including 8 short uphills; the mean speed during the tests was about $19.5 \mathrm{~km} / \mathrm{h}$ and the mean length of the tests was about $31.7 \mathrm{~km}$.

\section{PERformance ChaRACTERIZATION IN MAXIMUM ASSISTANCE MODE}

The aim of this test was to compare the energy used, extracted from the batteries, $\mathrm{E}_{\mathrm{U}}$ with the nominal energy $\mathrm{E}_{\mathrm{N}}$, when different control strategies are applied. The "Normal", for the Escape, and the "eBike", for the Zehus, modes were chosen. The Nine Continent kit does not allow any regulation of the assistance. For a fair comparison, the regenerative braking of the Zehus e-bicycle was disabled. The tests were started with the batteries fully charged and were interrupted by the activation of the battery undervoltage protection or in case of interruption of the electric motor support. The results are shown in Fig. 4 and in Table II. In particular, the electrical power and the energy extracted from the batteries are shown in Fig. 4(a) and Fig. 4(b), respectively. $E_{U}$ is reported versus time, normalized to the test duration. The two simplest systems, Atala and Nine Continent, reach almost the same performance, with over $92 \%$ of the $\mathrm{E}_{\mathrm{N}}$ delivered from the battery. During the tests of these systems the battery packs were discharged starting with a fully charged battery (cell voltages of about $4.18 \mathrm{~V}$ ) and ending when the undervoltage protection of the controller is activated (cell voltages of about $3.15 \mathrm{~V}$ ). For these two systems the SOC shown in Table II is defined as:

$$
\mathrm{SOC}=\frac{\mathrm{Q}_{\mathrm{N}}-\mathrm{Q}_{\mathrm{U}}}{\mathrm{Q}_{\mathrm{N}}}
$$

where $Q_{\mathrm{N}}$ is the nominal electrical charge of the battery and $Q_{\mathrm{U}}$ is the electrical charge used during the test.

The Zehus system delivers from the battery only $46.4 \%$ of the nominal energy $\mathrm{E}_{\mathrm{N}}$. During all the Zehus discharge tests, and during the recharges, the SOC indication on the display was always between $5 \%$ and $92 \%$ (the SOC definition it's unknown); the cell voltages range between $3.90 \mathrm{~V}$ (at $92 \%$ SOC) and $3.50 \mathrm{~V}$ (at $5 \%$ SOC). This happens because the BMS implements SOC-oriented algorithms avoiding the full exploitation of the battery energy avoiding deep discharges that reduce the life-cycle of Li-ion batteries [10]-[12].

It's noteworthy the fact that the battery pack of the Atala is rated for 500 cycle of charge and the battery of the Zehus e-bicycle is rated for 1000 cycle of charge with a SOH (State-Of-Health) of $70 \%$.

Table II: Performance characterization summary

\begin{tabular}{lccc|cc}
\hline e-bicycle & $\mathrm{E}_{\mathrm{N}}$ & $\mathrm{E}_{\mathrm{U}}$ & $\mathrm{E}_{\mathrm{U}} / \mathrm{E}_{\mathrm{N}}$ & \multicolumn{2}{|c}{$\mathrm{SOC}$} \\
& $\mathrm{Wh}$ & $\mathrm{Wh}$ & $\%$ & $\%$ Start & \% End \\
\hline Atala Escape & 360.0 & 343.2 & 95.3 & 100.0 & 1.7 \\
Nine Continenents & 360.0 & 334.4 & 92.9 & 100.0 & 6.0 \\
Zehus Bike+ & 154.8 & 71.8 & 46.4 & 92.0 & 5.0 \\
\hline
\end{tabular}


Table III: Zehus Bike+ road tests summary

\begin{tabular}{|c|c|c|c|c|c|c|c|c|c|c|c|c|}
\hline \multirow[t]{2}{*}{ Mode } & \multirow[t]{2}{*}{ e-brake } & \multicolumn{2}{|c|}{ SOC } & \multirow{2}{*}{$\begin{array}{l}\text { Trip } \\
\mathrm{km}\end{array}$} & \multirow{2}{*}{$\begin{array}{c}\mathrm{V}_{\text {mean }} \\
\mathrm{km} / \mathrm{h}\end{array}$} & \multirow{2}{*}{$\begin{array}{r}\mathrm{E}_{\mathrm{BAT}} \\
\mathrm{Wh}\end{array}$} & \multirow{2}{*}{$\begin{array}{l}E_{U} \\
W h\end{array}$} & \multirow{2}{*}{$\begin{array}{r}E_{R} \\
W h\end{array}$} & \multirow{2}{*}{$\begin{array}{r}\mathrm{E}_{\mathrm{BAT}} / \mathrm{km} \\
\mathrm{Wh} / \mathrm{km}\end{array}$} & \multirow{2}{*}{$\begin{array}{r}\mathrm{E}_{\mathrm{U}} / \mathrm{km} \\
\mathrm{Wh} / \mathrm{km}\end{array}$} & \multirow{2}{*}{$\begin{array}{r}\mathrm{E}_{\mathrm{R}} / \mathrm{km} \\
\mathrm{Wh} / \mathrm{km} \\
\end{array}$} & \multirow[t]{2}{*}{ Assistance } \\
\hline & & $\%$ Start & $\%$ End & & & & & & & & & \\
\hline \multirow{2}{*}{ eBike } & disabled & 92 & 5 & 32.0 & 21.2 & 71.8 & 71.8 & 0.0 & 2.24 & 2.24 & 0.00 & +++ \\
\hline & enabled & 91 & 5 & 31.7 & 19.3 & 74.7 & 85.5 & 10.8 & 2.36 & 2.70 & 0.34 & +++ \\
\hline Range extended & enabled & 92 & 49 & 46.8 & 16.8 & 49.2 & 65.1 & 15.9 & 1.05 & 1.39 & 0.34 & ++ \\
\hline \multirow{4}{*}{ Bike+ } & enabled & 5 & 32 & 7.7 & 19.8 & -6.1 & 0.2 & 6.3 & -0.80 & 0.02 & 0.82 & -- \\
\hline & enabled & 35 & 39 & 9.2 & 13.7 & -2.4 & 2.7 & 5.1 & -0.26 & 0.30 & 0.55 & $\ldots$ \\
\hline & enabled & 70 & 81 & 5.2 & 16.9 & -0.6 & 2.4 & 1.8 & -0.12 & 0.46 & 0.34 & -- \\
\hline & enabled & 92 & 90 & 6.1 & 16.8 & 1.8 & 3.5 & 1.7 & 0.30 & 0.58 & 0.28 & - \\
\hline
\end{tabular}

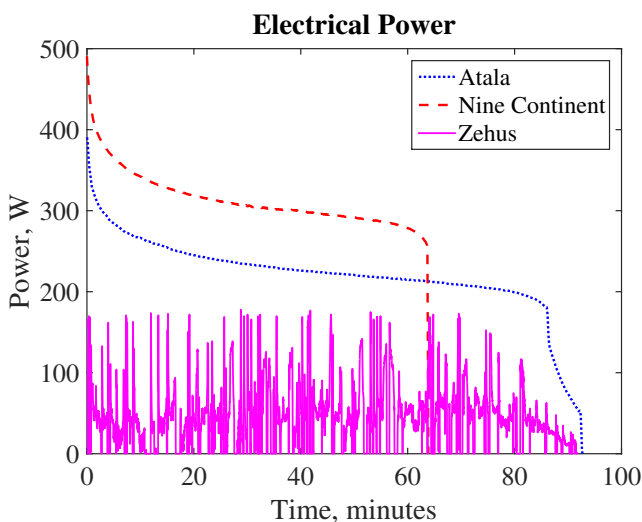

(a) Atala and Nine Continent curves are referred to the indoor bicycle trainer tests. The Zehus curve is referred to an on the road test

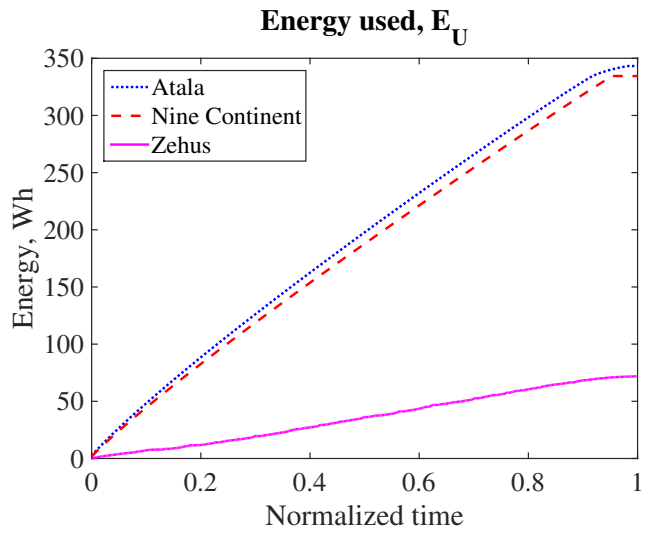

(b) It must be considered that Zehus weight 3 time less than Nine Continent and 2 time less than Atala

Figure 4: Performance characterization tests

\section{ENERGY STORAGE CONTROL STRATEGY AND PERFORMANCE CHARACTERIZATION}

The performance characterization was performed on the Zehus system since a BMS is implemented and different functioning modes are selectable. The tests in "eBike" mode were performed with the regenerative braking (e-brake) enabled or disabled. The test summary is shown in Table III, where a positive evaluation in the "Assistance" column means less effort for the user. The energy used by the motor $\mathrm{E}_{\mathrm{U}}$ and the energy recovered with regenerative braking $E_{R}$ were calculated from the acquired road test data. The energy extracted from the battery $\mathrm{E}_{\mathrm{BAT}}$ was calculated from the two previous quantities.

$$
\begin{aligned}
& \mathrm{E}_{\mathrm{U}}=\int_{0}^{\mathrm{t}_{\text {end }}} \mathrm{P}(\mathrm{t}: \mathrm{P}>0) d \mathrm{t} \\
& \mathrm{E}_{\mathrm{R}}=\int_{0}^{\mathrm{t}_{\text {end }}} \mathrm{P}(\mathrm{t}: \mathrm{P}<0) d \mathrm{t} \\
& \mathrm{E}_{\mathrm{BAT}}=\mathrm{E}_{\mathrm{U}}-\mathrm{E}_{\mathrm{R}}
\end{aligned}
$$

The test in "Range Extended" mode was interrupted before the complete discharge of the battery, as the final SOC indication was $49 \%$. The main difference with the "eBike" mode is the presence of an automatic regenerative braking algorithm implemented in the controller (i.e. the e-brake is automatically switched on during descends, when exceeding a target speed). In order to compare the results of the test in "Range Extended" and "eBike" modes, which ends at different SOC values, an estimation of the $\mathrm{E}_{\mathrm{U}}$ and $\mathrm{E}_{\mathrm{R}}$ was made basing on the mean values of $\mathrm{E}_{\mathrm{BAT}}$ calculated during other tests in "eBike" mode $\mathrm{E}_{\mathrm{BAT}}$ mean. The energy extracted from the battery when the $\mathrm{SOC}$ is $49 \%$ is $\mathrm{E}_{\mathrm{BAT}}(\mathrm{REm})$. Therefore,

$$
\begin{aligned}
& k=\mathrm{E}_{\mathrm{BAT} \_ \text {mean }} / \mathrm{E}_{\mathrm{BAT}}(\mathrm{REm}) \\
& \mathrm{E}_{i_{-} \mathrm{f}}=k \cdot \mathrm{E}_{i}(\mathrm{REm}), \quad i=\mathrm{U}, \mathrm{R}, \mathrm{BAT}
\end{aligned}
$$

where $E_{U_{-} f}, E_{B_{A} f}$ and $E_{R_{-} f}$ are the energy estimated for a test ending with a $5 \%$ SOC.

Table III also shows the specific energy per $\mathrm{km}$ for all the tests. Those indexes allow to figure out the amount of user assistance during the road tests. In particular, the values of $\mathrm{E}_{\mathrm{U}} / \mathrm{km}$ are the quantification of the user assistance (grades from "+ + +" to "- - -"). From a user perspective, the "eBike" mode allows trips of more than $30 \mathrm{~km}$ before recharging, avoiding the full discharge of the battery, in order to improve its life-cycles, but with the full assistance provided (grade " +++ " in Table III). In "Range Extended" mode, SOC-oriented algorithms reduce the level of assistance, in order to allow longer trip, up to $50 \mathrm{~km}$, without entirely discharging the battery and leaving an energy reserve (the test ended with $49 \%$ of SOC).

In "Bike+" mode, the vehicle is de-facto an hybrid system where the power source is provided by the user that recharges the embedded energy storage system, as a function of the SOC and the ride characteristics according to internal algorithms. As shown in Table III, $6.3 \mathrm{Wh}$ were regenerated in about $7.7 \mathrm{~km}$ during the test with SOC from 5 to $32 \%$. This energy was mainly regenerated when the user was pedaling at constant speed. 


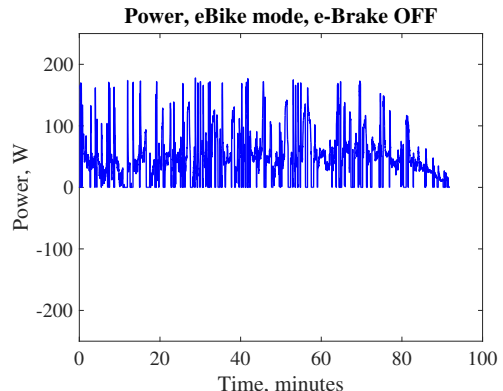

(a) Absence of negative values of power due to disabled e-brake. SOC from 92 to $5 \%$. Total distance $32 \mathrm{~km}$

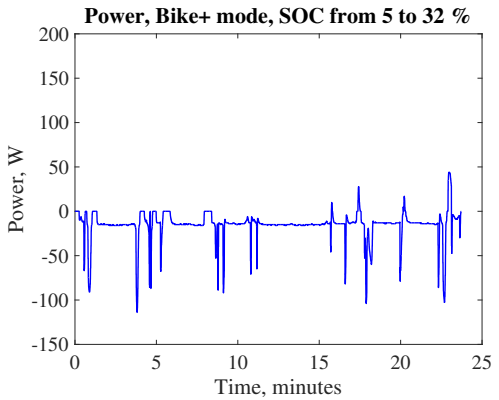

(d) Absence of positive values of power in the first part of the test due to low starting SOC. Energy regenerated even while the user is pedaling, e-brake enabled. Total distance $7.7 \mathrm{~km}$

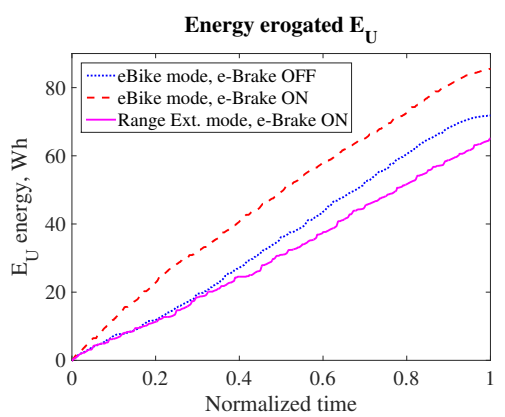

(g) Dotted and dashed curves are referred to the tests with battery from fully charged to $5 \%$ SOC. Solid curve is referred to the test ending with $49 \%$ SOC

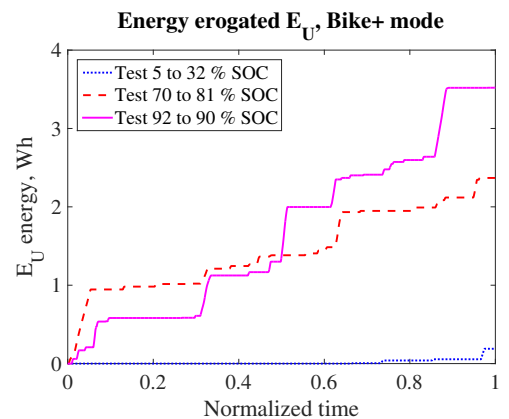

(j) Dotted curve is referred to the test low SOC, the energy delivered from the motor is limited to $0.2 \mathrm{Wh}$ due to SOC-maintaining integrated algorithms

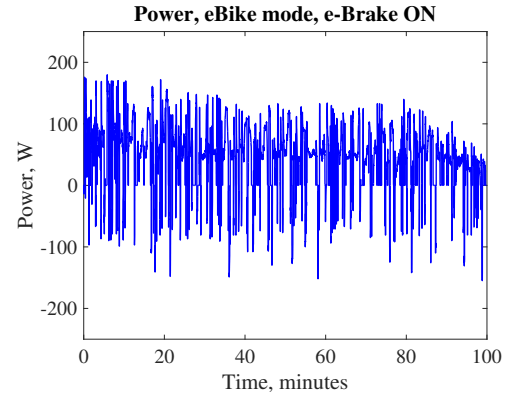

(b) SOC from 91 to $5 \%$, e-brake enabled. Total distance $31.7 \mathrm{~km}$

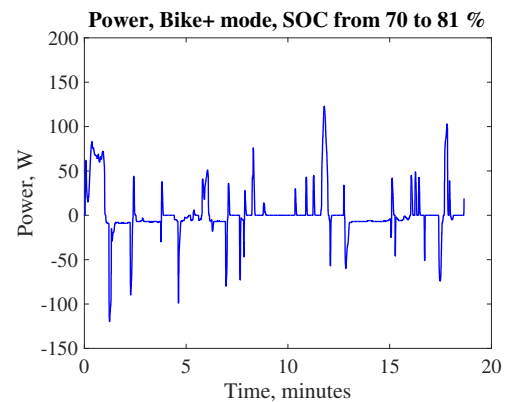

(e) SOC from 70 to $81 \%$. Energy regenerated even while the user is pedaling, e-brake enabled. Total distance $5.2 \mathrm{~km}$

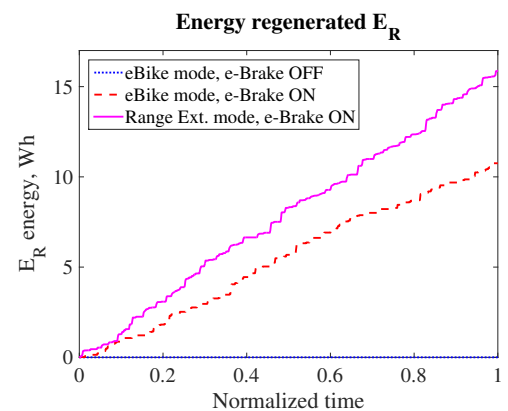

(h) Dotted curve is referred to the test with e-brake disabled. Dashed and solid curves are referred to the tests with e-brake enabled

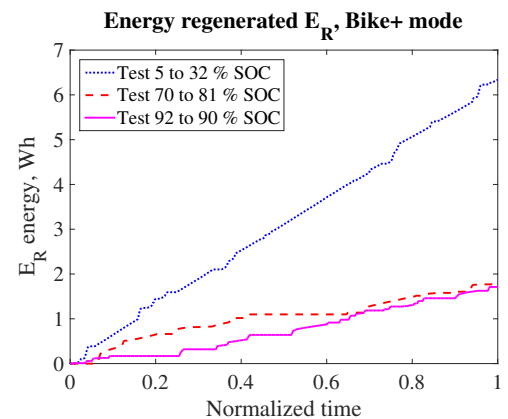

(k) The slope of the curves of the energy regenerated decrease for increasing range of SOC

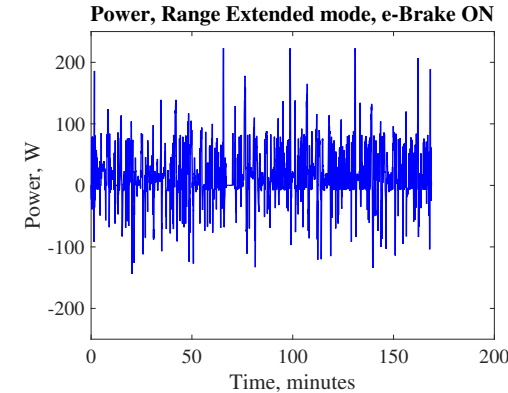

(c) SOC from 92 to $49 \%$, e-brake enabled. Total distance $46.8 \mathrm{~km}$

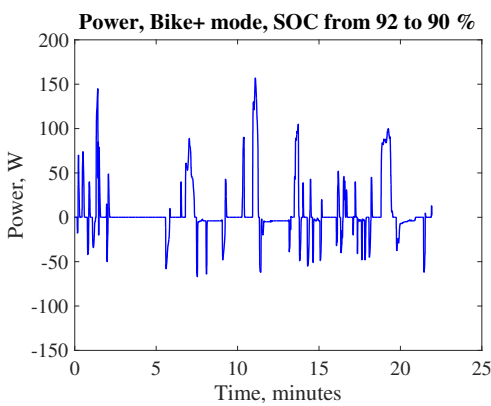

(f) SOC from 92 to $90 \%$, e-brake enabled. Total distance $6.1 \mathrm{~km}$

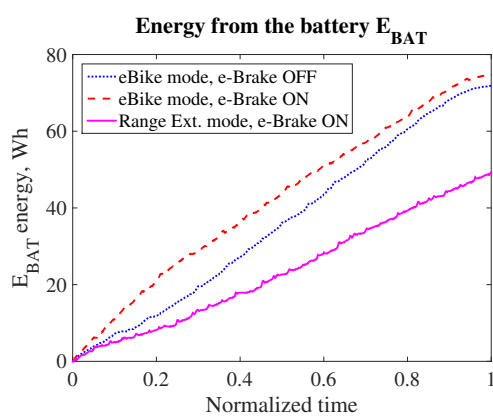

(i) Dotted and dashed curves are referred to the tests ending with $5 \%$ SOC. Solid curve is referred to the test ending with $49 \%$ SOC

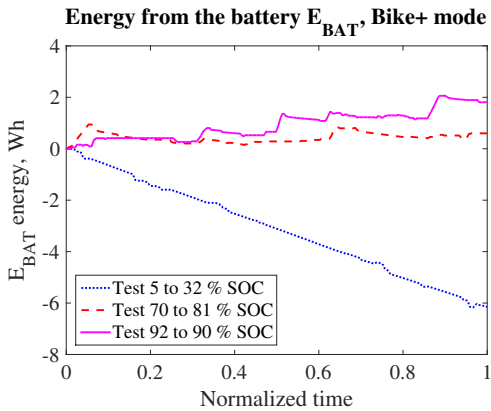

(l) The negative final value of the dotted curve shows the amount of energy from the user stored in the battery due to the integrated algorithms

Figure 5: Power and Energy curves during Zehus road tests. Negative values of power indicate regenerative braking and negative values of $\mathrm{E}_{\mathrm{BAT}}$ indicate the battery has been recharged 
The electrical power acquired during the tests in "eBike", "Range extended" and "Bike+" modes are shown in Figures 5(a) to 5(f). The negative values of the power are referred to the action of the e-brake, either actuated from the user, or automatically applied by the controller. The power diagram in Fig. 5(a) is always positive as e-brake is disabled. The regenerative braking power peaks in the Figures 5(b) and 5(c) are about $-150 \mathrm{~W}$ and the e-brake rms power values are $-68 \mathrm{~W}$ and $-30 \mathrm{~W}$, respectively. The e-brake power peaks are lower in Figures 5(d) to 5(f) for the "Bike+" mode tests, with the minimum at $-120 \mathrm{~W}$, whereas the e-brake power RMS value is about $-23 \mathrm{~W}$ for all the tests. The different applications of the user assistance based on the battery SOC are shown in Figures 5(d) to 5(f). For low values of SOC the pedaling assistance is almost disabled. Instead, the assistance level is similar to the "Range Extended" mode for high value of SOC. As mentioned above, the system recharges the battery with the kinetic energy provided by the user, for low values of SOC in this operating mode. This behavior is shown in Fig. 5(d) where we notice 6 flat spots with constant negative power of about $-15 \mathrm{~W}$.

Figures $5(\mathrm{~g})$ to $5(\mathrm{l})$ show the $\mathrm{E}_{\mathrm{U}}, \mathrm{E}_{\mathrm{R}}$ and $\mathrm{E}_{\mathrm{BAT}}$ values calculated from the data logged during the tests in "eBike", "Range extended" and "Bike+" modes. In particular, the energies during the road test in "eBike" mode (blu dotted and red dashed curves) and in "Range Extended" mode (magenta solid curve) are shown in Figures 5(g) to 5(i). Fig. 5(g) shows that the amount of energy used during the test in "Range Extended" mode is almost the same used in the "eBike" mode test with e-brake disabled. However, $49 \%$ SOC was left at the end of the "Range Extended" mode test. Figures 5(j) to 5(l) show the test results in "Bike+" mode. The dotted curve in Fig. 5(j) shows the behavior of the algorithms with a low battery SOC, when the user assistance is almost disabled. Instead, the dotted curve of Fig. 5(k) shows that the system is heavily harvesting energy from the user, in order to improve the battery SOC as show in Fig. 5(1), with a negative final value of $\mathrm{E}_{\mathrm{BAT}}$.

A summary of the results for the Zehus road tests are shown in Table IV, where it is also shown the estimation of the final energies $\left(E_{U_{f}}, E_{B A T} f\right.$ and $\left.E_{R_{f}}\right)$ for the test in "Range Extended" mode with an ending SOC of $5 \%$. Finally, it is also shown that the use of regenerative braking automatic algorithms leads to improvements of the overall performance of an e-bicycle, gaining up to $16 \%$ of the $\mathrm{E}_{\mathrm{U}} / \mathrm{E}_{\mathrm{N}}$ value, while preserving the health of the battery.

\section{CONCLUSION AND LESSON LEARNT}

The paper presented a measurement campaign for the performance characterization of energy storage systems in real-world electric bicycles. The campaign was made possible by the insertion of additional sensors, otherwise missing in the bicycles. Three vehicles with different electric motors, energy storage system size, inner sensors, human-vehicle interfaces and control strategies were characterized. The controller can implement sophisticated energy recovery strategies when braking. Advanced strategies can change the level of electric
Table IV: Zehus Bike+ road tests results summary

\begin{tabular}{|c|c|c|c|c|c|c|c|}
\hline Mode & e-brake & & $\begin{array}{l}\mathrm{E}_{\mathrm{BAT}} \\
\mathrm{Wh}\end{array}$ & $\begin{array}{l}\mathrm{E}_{\mathrm{BAT}} / \mathrm{E}_{\mathrm{N}} \\
\%\end{array}$ & $\begin{array}{l}\mathrm{E}_{\mathrm{U}} \\
\mathrm{Wh}\end{array}$ & $\underset{\%}{\mathrm{E}_{\mathrm{U}}} / \mathrm{E}_{\mathrm{N}}$ & $\begin{array}{l}\mathrm{E}_{\mathrm{R}} \\
\mathrm{Wh}\end{array}$ \\
\hline \multirow{2}{*}{ eBike } & disabled & & 71.8 & 46.4 & 71.8 & 46.4 & 0.0 \\
\hline & enabled & & 74.7 & 48.3 & 85.5 & 55.2 & 10.8 \\
\hline \multirow{2}{*}{$\begin{array}{l}\text { Range } \\
\text { extended }\end{array}$} & enabled & $*$ & 49.2 & 31.8 & 65.1 & 42.0 & 15.9 \\
\hline & enabled & $* *$ & 73.5 & 47.5 & 97.2 & 62.8 & 23.7 \\
\hline \multirow{4}{*}{ Bike+ } & enabled & & -6.1 & -3.9 & 0.2 & 0.1 & 6.3 \\
\hline & enabled & & -2.4 & -1.4 & 2.7 & 1.7 & 5.1 \\
\hline & enabled & & 0.6 & 0.4 & 2.4 & 1.6 & 1.8 \\
\hline & enabled & & 1.8 & 1.2 & 3.5 & 2.3 & 1.7 \\
\hline
\end{tabular}

* $49 \%$ SOC left at the end of the road test

** Energy estimated at the ending of a road test with a SOC of 5\%

assistance, depending on the desired trade-off between the comfort of the driver and the battery SOC. The achieved results prove that in simple e-bicycle controllers the energy storage system is forced to deep charge and discharge cycles (SOC from $99 \%$ to $1 \%$ ) to extract from the battery subsystem an energy value well over $90 \%$ of the nominal energy. Long covered distances (several tens of $\mathrm{km}$ with average speeds in the range $15-20 \mathrm{~km} / \mathrm{h}$ ) are achieved, but the deep charge/discharge cycles may reduce the battery life. More advanced control strategies aiming at preserving the battery SOC, together with regenerative braking, or increasing the pedaling effort of the user, can ensure very long battery duration (without even need of recharge). However, such efficient controls can lead to unsatisfactory comfort for the user. An intermediate control strategy, still with regenerative braking, can improve the user comfort while keeping long battery life-cycles and covered distances (several tens of $\mathrm{km}$ ), with a SOC kept at about $40-50 \%$ for a long period, without going above $95 \%$ or below $5 \%$. These advanced control strategies are only possible if a rich set of sensors including accelerometers and gyros, battery and motor voltage, currents and temperature, torque and speed are provided. They allow to meet the requirements of urban mobility with reduced battery size and weight leading to all-in-one systems.

\section{REFERENCES}

[1] “The global e-bike market," in INSG Insight, vol. 23, 2014, pp. 1-6.

[2] Aci italian traffic law, http://goo.gl/ub0rmu.

[3] A. Muetze and Y. Tan, "Electric bicycles - a performance evaluation," IEEE, Industry Applications Magazine, vol. 13, no. 4, pp. 12-21, 2007.

[4] O. Trescases et al., "A smart motor controller for e-bike applications," in IEEE Canadian Review, vol. Spring, 2003, pp. 16 - 19.

[5] V. Kumar et al., "Measurement of position (angle) information of bldc motor for commutation used for e-bike," in ICAES, 2013, pp. 316-318.

[6] Atala website, http://www.atala.it/.

[7] Nine continent website, http://www.9continent.com/

[8] Zehus website, http://www.zehus.it/.

[9] D. Schneider, "Ride by wire (resources-hand on)," IEEE Spectrum, vol. 50, no. 5, pp. 22-24, 2013.

[10] P. Ramadass et al., "Mathematical modeling of the capacity fade of li-ion cells," Journal of Power Sources, vol. 123, no. 2, pp. 230 - 240, 2003.

[11] J. Vetter et al., "Ageing mechanisms in lithium-ion batteries," Journal of Power Sources, vol. 147, no. 1-2, pp. $269-281,2005$.

[12] S. Peterson et al., "Lithium-ion battery cell degradation resulting from realistic vehicle and vehicle-to-grid utilization," Journal of Power Sources, vol. 195 , no. 8 , pp. $2385-2392,2010$ 